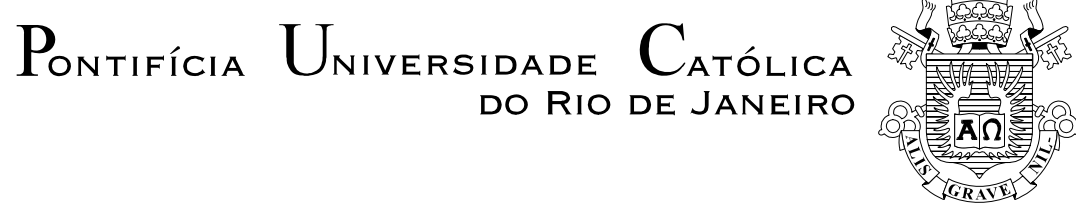

Renata Barreto Lacombe

Cala a boca já morreu. Quem manda aqui sou eu? Uma reflexão sobre a produção cultural da juventude contemporânea no universo das novas mídias

Tese de Doutorado

Tese apresentada ao Programa de Pós-graduação em Psicologia do Departamento de Psicologia da PUC-Rio como parte dos requisitos parciais para obtenção do título de Doutor em Psicologia Clínica.

Orientadora: Profa. Solange Jobim e Souza

Rio de Janeiro

Dezembro de 2011 


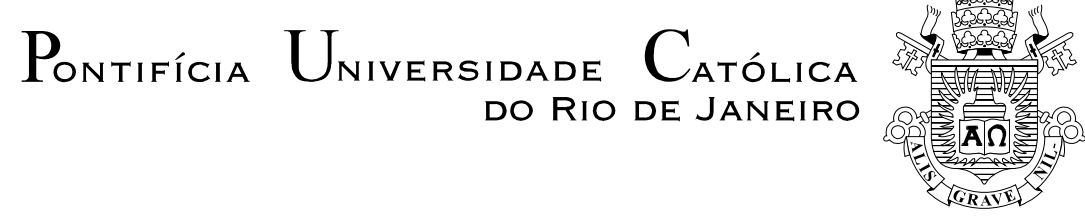

Renata Barreto Lacombe

\section{Cala a boca já morreu. Quem manda aqui sou eu? Uma reflexão sobre a produção cultural da juventude contemporânea no universo das novas mídias}

Tese apresentada como requisito parcial para obtenção do grau de Doutor pelo Programa de Pós-Graduação em Psicologia Clínica do Departamento de Psicologia do Centro de Teologia e Ciências Humanas da PUC-Rio. Aprovada pela Comissão Examinadora abaixo assinada.

Profa. Solange Jobim e Souza Orientadora Departamento de Psicologia - PUC-Rio

Profa. Rosália Maria Duarte Departamento de Educação - PUC-Rio

Prof. Nilton Gonçalves Gamba Júnior Departamento de Artes e Design - PUC-Rio

Prof. João Alves dos Reis Junior Fundação Roberto Marinho

Prof ${ }^{\mathrm{a}}$. Rita Marisa Ribes Pereira UERJ

Profa. Denise Berruezo Portinari Coordenadora Setorial de Pós-Graduação e Pesquisa do Centro de Teologia e Ciências Humanas - PUC-Rio

Rio de Janeiro, 19 de dezembro de 2011. 
Todos os direitos reservados. É proibida a reprodução total ou parcial do trabalho sem autorização da universidade, da autora e da orientadora.

\section{Renata Barreto Lacombe}

Graduada em 1995 pela Universidade Federal do Rio de Janeiro (UFRJ) em psicologia. Recebeu o título de mestre em psicologia clínica pela Pontificia Universidade Católica do Rio de Janeiro (PUC-RJ) em 2004 e, por essa mesma universidade, o título de doutora em 2011. Tem exercido a profissão como terapeuta clínica especializada em infancia e adolescencia e, também, como pesquisadora e consultora para instituições e empresas de mídia em geral.

\section{Ficha Catalográfica}

Lacombe, Renata Barreto

Cala a boca já morreu. Quem manda aqui sou eu? Uma reflexão sobre a produção cultural da juventude contemporânea no universo das novas mídias / Renata Barreto Lacombe; orientadora: Solange Jobim e Souza. - 2011.

$273 \mathrm{f} . ; 30 \mathrm{~cm}$

Tese (doutorado) - Pontifícia Universidade Católica do Rio de Janeiro, Departamento de Psicologia, 2011.

Inclui bibliografia

1. Psicologia - Teses. 2. Juventude. 3. Mídias. 4. Educação. 5. Cultura contemporânea. I. Souza, Solange Jobim e. II. Pontifícia Universidade Católica do Rio de Janeiro. Departamento de Psicologia. III. Título. 


\section{Resumo}

Lacombe, Renata Barreto; Jobim e Souza, Solange (Orientadora). Cala a boca já morreu. Quem manda aqui sou eu? Uma reflexão sobre a produção cultural da juventude contemporânea no universo das novas mídias. Rio de Janeiro, 2011. 273p. Tese de Doutorado - Departamento de Psicologia, Pontifícia Universidade Católica do Rio de Janeiro.

Reflexão sobre as mudanças na industria cultural contemporânea a partir da chegada das novas mídias, e sobre como tais mudanças estão afetando a produção cultural, a experiência e os processos de construção da subjetividade dos mais jovens, assim como o lugar social que ocupam.

\section{Palavras-chave}

Juventude; mídias; educação; cultura contemporânea. 


\section{Abstract}

Lacombe, Renata Barreto; Jobim e Souza, Solange (Advoisor). Shut up is out. Is that me who is on charge here? A view on contemporary youth cultural production in the context of the new medias. Rio de Janeiro, 2011. 273p. Doctorate Thesis - Departamento de Psicologia, Pontifícia Universidade Católica do Rio de Janeiro.

Study about the changes in the Contemporary Cultural industry influenced by the new medias emerged and how these changes are affecting the cultural production, the experiences and the processes of subjectivity's construction of the young people, and also the social place they are occupying nowadays

\section{Keywords}

Youth; medias; education; contemporary culture. 
Para meu sobrinho Antonio e meu afilhado André, crianças que amo especialmente. É por eles, em primeiro lugar, meu esforço em aliar conhecimento e esperança na construção do saber. 


\section{Agradecimentos}

À PUC - Rio, pelo auxílio concedido, sem o qual este trabalho não poderia ser realizado.

À Solange Jobim pela parceria, perseverança e confiança depositada no êxito desse processo de doutoramento. Não teria chegado até aqui sem sua orientação.

Ao grupo GIPS pelo apoio incondicional, atento e fraterno.

À Cristina Porto pela ajuda preciosa.

À Rita e Rosália pelo caminhar ao meu lado.

Ao Juva pelas palavras corretas.

Ao Alexandre por ter me ensinado a gostar da tecnologia.

À Denise por sua amizade verdadeira.

À banca pela disponibilidade.

Aos meus amigos por toda a força e compreensão.

Ás minhas irmãs por existirem.

Á minha mãe pelo amor incondicional.

Ao meu pai pela interlocução valiosa e saborosa. 
o preço da dúvida é a (em si

também)

descrença

não desprezo por, mas inveja de

quem tem

certeza. 


\section{Sumário}

$\begin{array}{ll}\text { Introdução } & 10\end{array}$

1. O cenário cultural (midiático) contemporâneo e seus sujeitos

1.1. Da tela da TV à tela do computador: mudanças nos usos sociais de mídia

1.1.1. A tela da televisão e o telespectador

1.1.2. A tela do computador e o internauta

1.1.3. Convergência e interatividade: todas as telas no mesmo quadrado

1.2. Uma visão da indústria cultural contemporanea 43

1.2.1. O hipertexto e o choc

1.2.2. A indústria cultural contemporânea: um esquema para chamar de seu

1.3. Uma proposta para pensar a cultura e consumo

2. A audiência infanto-juvenil contemporânea: da recepção à criação

2.1. Observação teórico-metodológica: o alicerce de nossa reflexão sobre a categoria infanto-juvenil

2.1.1. Uma visão sobre a infância (ou a juventude) como possibilidade do humano

2.2. Crianças e jovens como produtores de cultura: do conceito para a vida real

2.2.1. Audiência infanto-juvenil: conceito e via de reflexão

2.2.2. Um retrato das novas gerações midiáticas: dados e achados de pesquisas pelo mundo

3. Existência virtual e a produção dos "mais jovens"

3.1 Pesquisador Ciborgue e o sujeito ciborgue: novas formas de pesquisar e existir

3.2 A produção de cultura digital jovem: novas questões sobre a "fama" e o "trabalho"

3.2.1 Fama e Visibilidade

3.2.2 Visibilidade em uma nova esfera pública midiática

3.3 Produtores de conteúdo, trabalhadores ou simplesmente adolescentes em seus cotidianos midiáticos?

Conclusão 